Article

\title{
Effects of Agricultural Cooperative Society on Farmers' Technical Efficiency: Evidence from Stochastic Frontier Analysis
}

\author{
Ruopin $\mathrm{Qu}{ }^{1}{ }^{1}$, Yongchang $\mathrm{Wu}^{1}{ }^{1}$, Jing Chen ${ }^{1, *}$, Glyn D. Jones ${ }^{2,3}$, Wenjing $\mathrm{Li}^{2,3}$, Shan Jin ${ }^{2}$, \\ Qian Chang ${ }^{4}$, Yiying Cao ${ }^{5}$, Guijun Yang ${ }^{4}\left(\mathbb{D}\right.$, Zhenhong Li ${ }^{6}(\mathbb{D})$ and Lynn J. Frewer ${ }^{2}$ \\ 1 Institute of Agricultural Economics and Development, Chinese Academy of Agricultural Science, \\ Beijing 100081, China; tsqrp@126.com (R.Q.); wuyongchang@caas.cn (Y.W.) \\ 2 School of Natural and Environmental Sciences, Newcastle University, Newcastle upon Tyne NE1 7RU, UK; \\ glyn.d.jones@fera.co.uk (G.D.J.); Li.Wenjiing@newcastle.ac.uk (W.L.); S.Jin13@newcastle.ac.uk (S.J.); \\ lynn.frewer@newcastle.ac.uk (L.J.F.) \\ 3 FERA Sciences Ltd., National Agri-Food Innovation Campus, Sand Hutton YO41 1LZ, UK \\ 4 National Engineering Research Center for Information Technology in Agriculture, Beijing 100097, China; \\ changliang_2008@yeah.net (Q.C.); guijun.yang@163.com (G.Y.) \\ 5 RSK ADAS Ltd., Spring Lodge, 172 Chester Road, Helsby WA6 0AR, UK; yiying.cao@adas.co.uk \\ 6 School of Engineering, Newcastle University, Newcastle upon Tyne NE1 7RU, UK; \\ Zhenhong.Li@newcastle.ac.uk \\ * Correspondence: chenjing@caas.cn
}

Received: 10 August 2020; Accepted: 24 September 2020; Published: 5 October 2020

\begin{abstract}
The impact of agricultural cooperatives on apple farmers' technical efficiency (TE) in China was examined. The cooperatives were divided into two groups: a collective marketing group for farmers and an equivalent non-marketing group that did not provide a marketing service, although other functions remained the same. Using the propensity score matching (PSM) procedure and stochastic production frontier (SPF) modelling, cooperatives' key functions that potentially increase farmers' TE can be identified. The results indicate that membership of either group is positively related to yield. However, cooperatives that were not engaged in marketing achieved higher TE than non-members. This suggests that policy makers should encourage cooperatives to focus on activities that do not include direct marketing to increase TE in apple production in China.
\end{abstract}

Keywords: agricultural cooperatives; technical efficiency; propensity score matching; stochastic production frontier; apple production; China

\section{Introduction and Literature Review}

Increasing smallholder farmers' productivity and technical efficiency (TE) may facilitate agricultural development in countries like China where small-scale smallholder production predominates. The primary objective of this study is to analyze cooperatives' impact on TE. This research theme is worth exploring for four reasons. First, among China's agricultural producers, $99.2 \%$ are small-scale farmers, and their efficiency is, on average, much lower than those in developed countries [1]. Improving the technical efficiency (TE) of small-scale farmers would significantly improve China's overall production efficiency. Second, agricultural cooperatives may enable smallholder farmers in China to increase productivity and efficiency more cheaply than through other means, such as hiring more labor or using improved seeds and agrochemicals. Third, this study distinguished cooperatives by functions to compare their TE, and the implications of this paper can also be used by other developing countries and transition countries that use cooperatives to enhance agricultural production. 
Last, compared with developed countries such as the United States and Germany, the development of cooperatives in China needs to be further improved. Therefore, to explore the impact of cooperatives on agricultural production is conducive to the formulation of sustainable agricultural production policy recommendations. TE is defined as producing a given level of output using the minimum feasible amounts of inputs and using the same technology in production systems as previously applied, avoiding investment in new technologies.

\section{Literature Review}

It is notable that cooperatives were established earlier in Western countries than in China. Internationally, research has focused on understanding how to optimize regulations and governance structures associated with the sustainable development of cooperatives [2-4]. For example, Bijman et al. (2012) have identified three types of cooperative governance models in Western countries, based on the distribution of decision-making power between cooperatives' governing bodies and external managers: traditional, managerial, and corporate, with the board's power decreasing across these three groups from direct management to minor supervision [5]. Indeed, numerous studies have investigated the functions of cooperatives at both the micro level (examining impacts in relation to farmer and organizational behaviors) and the macro level (where regional or country perspectives are investigated), e.g., [6-9]. The results indicate that the impacts of co-operative membership are mixed and may be dependent on the local context. For example, in China, the impact of farmers' cooperative membership may also be influenced by national policy initiatives.

After the implementation of the Law of the People's Republic of China on Specialized Farmers Cooperatives in 2007 (revised in 2017 and 2018), together with associated supporting governmental policies, many farmers' cooperatives were established that aimed to take advantage of tax benefits and government subsidies linked to these policies [10]. Notably, some cooperatives were established by agricultural corporates rather than by farmers to facilitate acquisition of tax advantages [11]. Deng et al. (2016) argued that the lack of controls on agricultural product quality, the high level of heterogeneity in quality associated with China's smallholder farmers' products, the small-scale operation of most farmers, and the lack of effective support from external resources have resulted in problems in reducing transaction costs [10]. Against this, cooperatives are expected to increase farmers' price-negotiating power and to widen their marketing and information channels [12]. Thus, cooperatives that "sell" products on behalf of farmers have the potential to increase TE. The aim of the research presented here was to understand which factors associated with Chinese cooperatives are likely to improve the TE of their members, in particular the "selling" or "marketing" function. The focus of the research is on apple production. China is the largest country in terms of apple consumption, (FAOSTAT (Food and Agriculture Organization of the United Nations statistics data), although the TE associated with their apple production is poor.

Some studies have attempted to differentiate the TE advantages delivered by various types of cooperative. For example, Wu (2013) researched the efficiency associated with six types of farmers' cooperative in the Guangzhou and Anhui provinces in China according to their managerial pattern [13]. 'Enterprise' type cooperatives that aimed to support product processing and marketing were the most efficient, followed by the 'supply and marketing' type, while the 'ambiguous' type scored the lowest [13]. In order to explore the relationship between type of cooperative and the TE of farmers, Liu et al. (2019) used data from beef cattle farmers in China to analyze the impact of different organizational models on beef cattle farmers' TE and found that membership of cooperatives provided the greatest increase in efficiency [14]. Data from fruit farmers in Anhui were examined to understand the effect of farmers' participation in cooperatives on their TE [15]. The findings suggested that, when sample selection bias arising from observed factors (e.g., age, gender, education, etc.) was not considered, farmers' participation in cooperatives was associated with a significant improvement in their production TE. However, when sample selection bias was eliminated by applying propensity score matching (PSM), participation in cooperatives showed no substantial impact on TE. Two studies 
have investigated cooperative membership on apple farmers in China. Ma and Abdulai (2016) used an endogenous switching regression model to account for sample selection bias and examined the effect of cooperative membership on farmers' income [16]. The results indicated that cooperative membership improved farmers' apple yield and income. Another study examined the impact of cooperative membership on apple farmers' efficiency level using the stochastic production frontier (SPF) model, which was combined with PSM to account for the observable selectivity bias [12]. The results demonstrated that cooperative members attained higher efficiency than non-members [12].

Previous research has assessed the mechanisms and functions of agricultural cooperatives, including their impacts on farmers' TE and income; however, understanding the impact of smallholder farmer's cooperatives has less frequently been the focus of research. In addition, given that the cooperative mechanism emerged much later in China than in Western countries, a considerable number of Chinese cooperatives were established in order to obtain benefits from related policies (e.g., tax benefits) and did not provide services to facilitate agricultural practice and business [10]. Therefore, investigations into the actual impacts of cooperatives on smallholder farmers' efficiency must consider the service delivery functions of cooperatives, including the selling and marketing functions. The importance of assessing this in the context of apple production in China is underscored by the fact that China is the largest apple-producing country in the world by quantity; however, its production efficiency is only one third that of the most efficient country (FAOSTAT).

In the research presented here, The SPF model was applied to estimate the apple production function and the efficiency level of each group. Specifically, this paper will classify the cooperatives according to the services they provide; in particular, whether they provide selling and marketing functions. This will enable comparison between those cooperatives with marketing functions and those which offer similar functions other than these. In addition, PSM will be applied to match farmers who are members of cooperatives with those who are not, according to a household's characteristics. The results will provide evidence-based recommendations for policy makers to optimize the development of the cooperative model.

\section{Data}

The survey was conducted face-to-face by trained enumerators, with at least one researcher (named as an author on this paper) present to ensure the quality of the data collection. Of the 39.23 million tons of apples produced in China in 2018, 67\% were delivered by four provinces: Shanxi (3.77 million tons), Shaanxi (10.08 million tons), Shandong ( 9.52 million thousand), and Gansu (2.92 million tons) [17]. Of the 203 million people in the four provinces, 8.44 million people live in the rural area, where agricultural production is the main income source [17]. On this basis, these four provinces were selected for sampling in the present study. Two regions in each province were selected for study, one representing one of the best (that is, best-known and highest-yield) apple-producing areas in the province and one representing middle-ranking (that is, medium yield) production areas. At the county level, six villages were randomly selected in an effort to minimize selection bias. In each village, ten farmers were chosen randomly to be included in the study. Four hundred eighty farmers participated in the survey; 120 from each province selected. The questionnaire was pre-tested in Shandong at the beginning of 2019, refined, and then distributed in October 2019. A total of 480 questionnaires were collected, of which 451 included complete responses. One hundred sixty-two cooperative members and 289 non-members returned complete questionnaires. Ethical approval for the study was granted by one of the cooperative institutes in 2019 (Ref: 18226/2019).

Farmers who had joined a cooperative were asked what services the cooperative provided or how the cooperative functioned. Eleven distinct services were identified: apple marketing, buying/selling fertilizers and pesticides, labor hire, fertilization management, pesticides management, production training, quality tracing, apple storage, apple processing (into juice or other processed foods), financial services, and other production management functions. The cooperatives were divided into two types based on their apple marketing function: those that helped with apple sales were classed as 
the marketing group, while those that did not help with apple sales were the non-marketing group. Non-members, and members of the non-marketing cooperatives, wait for wholesalers to come and collect their apples, or sell them at local markets, where they could potentially negotiate prices with wholesalers and customers.

\section{Method}

\subsection{Stochastic Production Frontier Model (SPF)}

Two methods have been widely used in the literature to estimate the technical efficiency of crop production. These include parametric methodologies such as the stochastic production frontier (SPF) model $[12,18]$ and non-parametric methodology such as data envelope analysis (DEA) [19]. Of these approaches, the DEA method does not assume random errors and assigns all inefficiency to the inefficiency term, making it quite sensitive to outliers and stochastic errors, especially for small datasets. In comparison, the SPF approach assigns inefficiency both to random errors and to the inefficiency term; the results generated by SPF reports the percentage of stochastic errors and inefficiency term in constituting the total inefficiency. Because the efficiency of agricultural production is sensitive to random errors and unpredictable weather conditions, the hypothesis is that stochastic errors are a crucial element in determining efficiency; therefore, the SPF method was applied. For analytical purposes, a farmer is assumed to be either a non-member, marketing cooperative member, or non-marketing cooperative member. The SPF model proposed by Aigner, Lovell, and Schmidt (1977) is written as follows [20]:

$$
\begin{gathered}
y_{i}=f\left(x_{i}, \beta+M_{i}\right) \xi_{i} e^{v_{i}} \\
e^{v_{i}}=v_{i}-u_{i}
\end{gathered}
$$

where $y_{i}$ is the output of the $i$-th farmer, $x_{i}$ is the combined inputs of the farmer, $\beta$ is the unknown parameters to be estimated, and $\xi_{i}$ is the efficiency level of the $i$-th farmer. $\xi_{i}$ is in the range between 0 and 1 ( 0 for completely inefficient, 1 for completely efficient). $e^{v_{i}}$ is the symmetric random term representing stochastic noise, composed of the stochastic noise term $v_{i} \sim N\left(0, \sigma_{v}^{2}\right)$ and the truncated-normal distributed stochastic inefficiency term, $u_{i} \sim N^{+}\left(\mu, \sigma_{u}^{2}\right)$. Because we want to examine the impact of cooperative membership on technical efficiency, a dummy variable representing cooperative membership was added into the model. $M_{i}$ is cooperative membership ( 0 for non-member and 1 for member).

Based on the nature of apple production and the likelihood ratio test, the Cobb-Douglas function was applied as the production function; using the Cobb-Douglas production model, and taking log on both sides, it is written as follows:

$$
\ln \left(Y_{i}\right)=\beta_{0}+\sum_{j=1}^{6} \beta_{j} \ln x_{i}+\psi_{i} M_{i}+\omega_{i}
$$

where $\ln$ is the natural logarithm; $Y_{i}$ is the output of the $i$-th farmer, which is the revenue per mu $(1 / 15 \mathrm{ha})$ of the $i$-th farmer in 2018, calculated in yuan. $x_{i}$ is the aggregated inputs, which are aggregated into six categories: expenses on hired labor (yuan), expenditure on fertilizer, pesticides, and bags (bags used to cover the apples for better coloring, which is measured in yuan/mu), and number of family workers, which are all calculated per mu. $\beta_{0}$ is a constant term. $\beta_{j}$ and $\psi_{i}$ are parameters to be estimated. $\omega_{i}$ is a random error term following the $N\left(\mu, \sigma_{\omega}^{2}\right)$ distribution. Farmers who did not harvest any apples or expend on inputs were included, with their output and input set to 0 . Outputs and inputs are calculated in yuan to reflect the influence of cooperatives' price-negotiating and marketing power; additionally, monetary value enables us to capture the difference in apple quality between farmers [12]. 
Utilizing the model, efficiency is calculated as follows:

$$
T E_{i}=\frac{Y_{i}}{e^{f\left(x_{i}, \beta\right)+V_{i}}}=\exp \left(-U_{i}\right)=Y_{i} / Y_{i}^{*}
$$

where $Y_{i}$ is the actual output of the $i$-th farmer. $Y_{i}^{*}$, called the 'frontier', which is the greatest possible output that can be produced by using the same available inputs. When the error term is 0 , the efficiency of the $i$-th farmer is 1 .

However, this relies on an underlying assumption that all farmers have access to the same technology and share the same production frontier, which might not be the case. For example, with technical guidance of agricultural cooperatives, cooperative members may produce apples at different production frontiers compared with non-members. Following the procedure proposed by Bravo-Ureta et al. (2012) to test technology disparity, a likelihood ratio test can be employed, as follows [21]:

$$
L R=-2 *(\operatorname{Ln} L p-(\operatorname{LnLm}+\operatorname{LnLnm})
$$

where $L n L p$ denotes the log likelihood of the pooled sample obtained in the SPF model and LnLm and LnLnm are the log likelihoods of the cooperative members and non-members. The null hypothesis is that members and non-members share the same production function; the rejection of the null hypothesis would suggest that cooperative members operate at different production frontiers from non-members. In this case, separate production functions for cooperative members (marketing and non-marketing) and non-members must be estimated. The estimation specifications can be specified as follows:

$$
\begin{gathered}
\text { Cooperative members : } \ln \left(Y_{i}\right)=\eta_{0}+\sum_{j=1}^{6} \eta_{j} \ln x_{i}+\tau_{i} \\
\text { Non-members : } \ln \left(Y_{i}\right)=\xi_{0}+\sum_{j=1}^{6} \xi_{j} \ln x_{i}+\varphi_{i}
\end{gathered}
$$

where $Y_{i}$ and $x_{i}$ are defined as above, $\eta_{0}$ and $\xi_{0}$ are constant terms, $\eta_{j}$ and $\xi_{j}$ are parameters to be estimated, and $\tau_{i}$ and $\varphi_{i}$ are random errors.

\subsection{Propensity Score Matching (PSM)}

Farmers self-select themselves to be cooperative members or non-members [9,12]. There is a lack of data about TE available prior to a farmer joining a cooperative, and it would therefore be difficult to compare the change in TE for each household. Using Abdulai and Abdulai's (2017) framework for selection bias correction, propensity score matching (PSM) is used to reduce the bias arising from observed factors [22]. The rule for joining a cooperative is as follows:

$$
\begin{gathered}
M_{i}^{*}=a Z_{i}+e_{i} \\
\text { if } U i^{m}>U i^{n m}, M_{i}=1 \text {, if } U i^{m}<U i^{n m}, M_{i}=0
\end{gathered}
$$

where $U i^{m}$ is the expected utility of joining a cooperative and $U i^{n m}$ is the expected utility of not joining a cooperative. When the expected utility of joining is greater than that of not joining, the farmer chose to join; otherwise, the farmer chose not to join. $M_{i}$ is the membership status of the $i$-th farmer: 1 is member, 0 is non-member. $M_{i}^{*}$ is the propensity for the $i$-th farmer to join a cooperative, calculated using exogenous variables denoted by $Z_{i} . a$ is a vector of parameters to be estimated and $e_{i}$ is an error term that is assumed to follow the normal distribution and have a mean of 0 .

The PSM application enables the "matching" of farmers who did and did not join cooperatives, based on their observed characteristics. By matching farmers based on these observable characteristics, the net effect of being a member of the cooperative can be assessed. In the PSM application, a binary choice model (a logit model in this study) is used to generate a score that denotes the 'propensity' for the farmer to join a cooperative based on the chosen characteristics. Households with similar scores are 
those with similar characteristics; therefore, matching their scores in the efficiency study will generate more convincing results.

In implementing PSM, several techniques, including kernel-based matching, nearest-neighbor matching, radius matching, and stratification matching, can be used to match farmers' scores [23]. In this study, the nearest-neighbor matching technique was employed as it is the most commonly used in previous studies [22,24]. This technique can reduce selection bias more effectively, with four neighbors for one match and a caliper of 0.01 to ensure that the difference between neighbors' propensity scores does not exceed 1\%. Replacement was accepted in order to reduce the number of omitted samples. A logit model was used to calculate the propensity scores based on the selected exogenous variables, and samples with less than $1 \%$ difference scores will be matched. The exogenous variables chosen include age, gender, education (in years), orchard size (in $\mathrm{mu}$ ), and number of family members laboring on the farm. This procedure produced a total of 196 matched samples for the marketing group, composed of 134 non-members and 62 members. For the non-marketing group, this procedure generated 259 matched samples, with 175 non-members and 84 members. Each member had two to three non-members as comparators.

\subsection{Description of the Variables}

The variables used in this analysis are listed in Table 1. The variables used for marketing and non-marketing cooperatives are identical. The reason for using these five variables for PSM is that they are the most easily observable factors affecting the farmer's choice of whether or not to join a cooperative. Matching these variables helps to group together farmers with similar characteristics in order to evaluate the impact on the cooperative. For the SPF model, all variables except the dummies and family laborers are calculated in yuan to reflect the price-setting and negotiating power of cooperatives.

Table 1. Description of variables used in propensity score matching (PSM) and stochastic production frontier $(\mathrm{SPF})$.

\begin{tabular}{|c|c|}
\hline Variable & Description \\
\hline \multicolumn{2}{|l|}{ Variables used in PSM } \\
\hline Age & Age of the farmer in years \\
\hline Gender & $\begin{array}{l}\text { Gender of the farmer interviewed, } \\
\quad 1=\text { male, } 0=\text { female }\end{array}$ \\
\hline Education & Education duration in years \\
\hline Orchard Size & Orchard size in mu1 \\
\hline Family Labor & Number of family-member laborers in the household \\
\hline \multicolumn{2}{|l|}{ Variables used in SPF } \\
\hline Output (ln) & Revenue from apple yields in 2018 (yuan/mu) \\
\hline Membership & Cooperative membership, $1=$ member, $0=$ non-member \\
\hline Hired labor (ln) & Expense on hired labor (yuan/mu) \\
\hline Fertilizer $(\ln )$ & Expense on fertilizer (yuan/mu) \\
\hline Pesticides (ln) & Expense on pesticides (yuan/mu) \\
\hline Bags $(\ln )$ & Expense on bags (yuan/mu) \\
\hline Family laborers (ln) & Number of family laborers (days/mu) \\
\hline
\end{tabular}

$11 \mathrm{mu}=1 / 15 \mathrm{ha}, 21$ yuan $=0.14 \mathrm{USD}$ at the time of writing.

\section{Results}

\subsection{Propensity Score Matching (PSM)}

The descriptive data for unmatched and matched sample selection variables are presented in Tables 2 and 3, respectively. The average age for all groups is just above 50, which is a concern to most farmers as the average age of apple producers is increasing $[25,26]$. In all groups, people who participate 
in apple production are mainly males. Females usually provide help to their husbands, but they seldom engage in production management; they usually referred to their husbands when approached for interview because they had no decision-making power [27]. Before matching, the non-marketing group had significantly more females than non-members, but the difference is removed after matching. The average education level for all farmers is high school, generally not reaching year 9. Non-marketing members differ from non-members with regards to orchard size, as the difference is still strongly significant after matching, even though the difference has been reduced from 14.334 to 3.614. Marketing group members also have larger orchards than non-members on average, though the difference is not significant. The mean number of family-member laborers is around two, with unmatched non-members having the least and matched non-members for the marketing group having the most. However, no significant difference exists between these groups. Apple production is labor-intensive, which makes family labor a crucial factor in determining the expense for each household, but number of family laborers does not necessarily equal effort.

Table 2. Mean and differences of PSM variables, unmatched sample.

\begin{tabular}{ccccccc}
\hline \multirow{2}{*}{ Variable } & \multicolumn{3}{c}{ Non-Marketing Members } & \multicolumn{3}{c}{ Marketing Members } \\
\cline { 2 - 6 } & Non-members & Members & Mean-Diff & Non-members & Members & Mean-Diff \\
\hline Age & 52.717 & 51.894 & 0.823 & 52.717 & 51.154 & 1.564 \\
Gender & 0.902 & 0.824 & $0.079 * *$ & 0.902 & 0.892 & 0.010 \\
Education & 8.159 & 8.565 & -0.405 & 8.159 & 8.292 & -0.133 \\
Orchard size & 10.633 & 24.967 & $-14.334 * *$ & 10.633 & 16.245 & -5.611 \\
Family labor & 1.982 & 2.024 & -0.042 & 1.982 & 2.062 & -0.080 \\
Sample Size & 276 & 86 & 362 & 276 & 66 & 342 \\
\hline \multicolumn{7}{c}{$* * 0.01}$.
\end{tabular}

Table 3. Mean and differences of PSM variables, matched sample.

\begin{tabular}{|c|c|c|c|c|c|c|}
\hline \multirow{2}{*}{ Variable } & \multicolumn{3}{|c|}{ Non-Marketing Cooperatives } & \multicolumn{3}{|c|}{ Marketing Cooperatives } \\
\hline & Non-Members & Members & Mean-Diff & Non-Members & Members & Mean-Diff \\
\hline Age & 52.200 & 51.821 & 0.379 & 50.75 & 51.15 & -0.399 \\
\hline Gender & 0.880 & 0.821 & 0.059 & 0.903 & 0.887 & 0.0160 \\
\hline Education & 8.331 & 8.524 & -0.192 & 8.575 & 8.274 & 0.300 \\
\hline Orchard size & 9.746 & 13.360 & $-3.614^{* *}$ & 11.12 & 11.98 & -0.862 \\
\hline Family labor & 2.011 & 2.048 & -0.036 & 2.104 & 2.081 & 0.0240 \\
\hline Sample Size & 175 & 84 & 259 & 134 & 62 & 196 \\
\hline
\end{tabular}

Figures 1 and 2 present the bias reduction results after the PSM procedure. The bias arising from the exogenous factors will cause inaccuracy when comparing TE between cooperative members and non-members. However, applying the PSM procedure will reduce it to an acceptable range. Most bias across covariates has been reduced to within $10 \%$ for both groups, which proves the PSM procedure has been successful.

\subsection{Stochastic Production Frontier (SPF)}

The mean and differences of variables used for the stochastic production frontier are summarized in Table 4 before matching and in Table 5 after matching. It is notable that, before and after matching, the average output of cooperative members is lower than that of non-members. However, the significance of the difference for the marketing group disappears after matching. Before and after matching, family laborers associated with cooperative members work significantly less in the field than non-members in both groups. In general, non-members spend more on fertilizers and pesticides than members. The expenditure for the matched non-members is significantly higher than the marketing members, which suggests that cooperatives succeed in lowering expenses and reducing the usage of fertilizer and pesticides for its members. However, members in all groups have 
higher expenses on bags than non-members, though not significantly. The hired labor expense does not vary significantly across the groups.

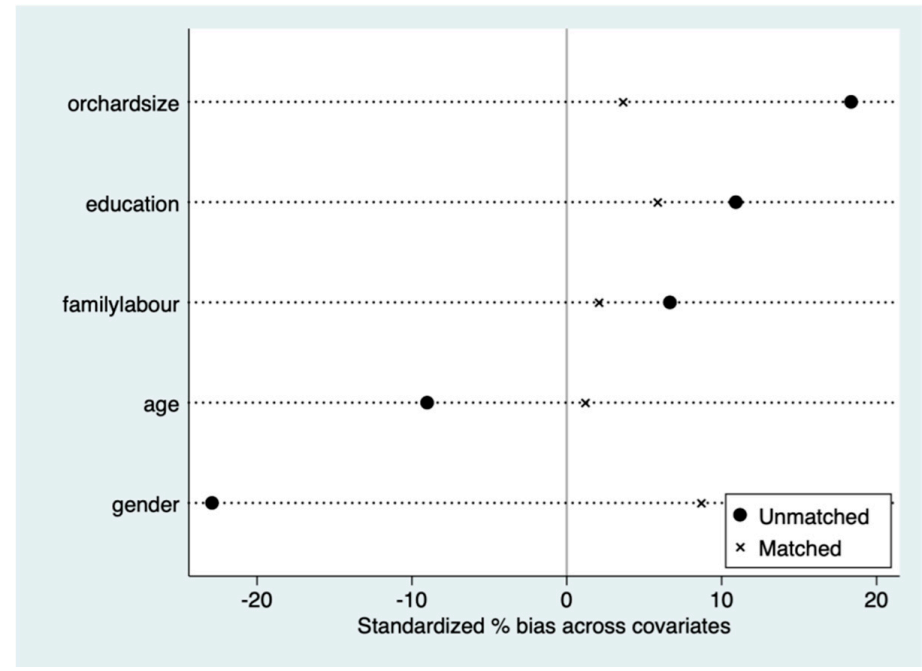

Figure 1. Bias reduction results of non-marketing cooperatives.

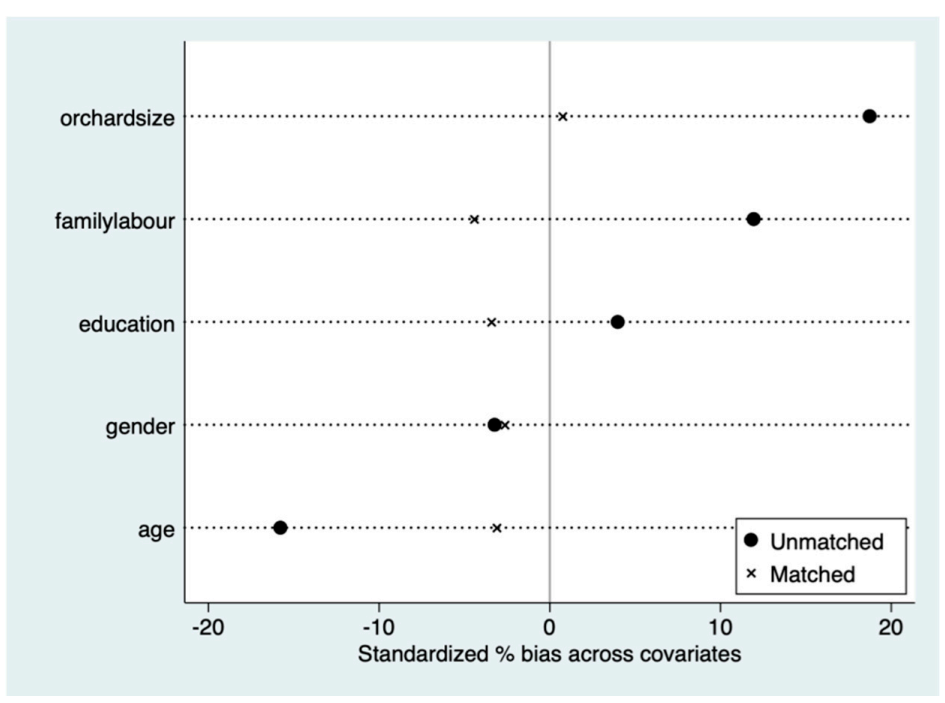

Figure 2. Bias reduction results of marketing cooperatives.

Table 4. Mean and differences of SPF variables, unmatched.

\begin{tabular}{ccccccc}
\hline \multirow{2}{*}{ Variables } & \multicolumn{3}{c}{ Non-Marketing Cooperatives } & \multicolumn{2}{c}{ Marketing Cooperatives } \\
\cline { 2 - 6 } & Non-Members & Members & Mean-Diff & Non-Members & Members & Mean-Diff \\
\hline Output(ln) & 8.082 & 7.766 & $0.316^{* *}$ & 8.082 & 7.775 & $0.307^{*}$ \\
Fertilizer(ln) & 7.238 & 7.099 & 0.139 & 7.238 & 7.241 & -0.003 \\
Pesticides(ln) & 5.540 & 5.519 & 0.022 & 5.540 & 5.395 & 0.145 \\
Bags(ln) & 6.805 & 6.939 & -0.135 & 6.805 & 6.917 & -0.112 \\
Hired labor(ln) & 3.189 & 3.582 & -0.393 & 3.189 & 2.921 & 0.268 \\
Family labor(ln) & 6.496 & 4.061 & $2.435^{* * *}$ & 6.496 & 3.875 & $2.621^{* * *}$ \\
Sample size & 278 & 86 & 364 & 278 & 65 & 343 \\
\hline
\end{tabular}


Table 5. Mean and differences of SPF variables, matched.

\begin{tabular}{ccccccc}
\hline \multirow{2}{*}{ Variables } & \multicolumn{3}{c}{ Non-Marketing Cooperatives } & \multicolumn{2}{c}{ Marketing Cooperatives } \\
\cline { 2 - 6 } & Non-Members & Members & Mean-Diff & Non-Members & Members & Mean-Diff \\
\hline Output(ln) & 8.071 & 7.771 & $0.300 *$ & 8.060 & 7.770 & 0.290 \\
Fertilizer(ln) & 7.226 & 7.108 & 0.118 & 7.280 & 7.243 & 0.037 \\
Pesticides(ln) & 5.549 & 5.532 & 0.017 & 5.593 & 5.339 & $0.254^{*}$ \\
Bags(ln) & 6.840 & 6.873 & -0.034 & 6.735 & 6.859 & -0.125 \\
Hired labor(ln) & 3.463 & 3.516 & -0.053 & 3.149 & 2.993 & 0.156 \\
Family labor(ln) & 6.513 & 4.106 & $2.407^{* * *}$ & 6.485 & 3.908 & $2.577^{* * * *}$ \\
Sample size & 175 & 84 & 259 & 133 & 62 & 195 \\
\hline \multicolumn{7}{c}{$p<0.05 ; * * *<0.001}$. \\
\end{tabular}

The unmatched and matched results from SPF are in Tables 6 and 7, respectively. This study reported $t$-statistics instead of standard errors because $t$-statistics are determined by the coefficient of each variable and its corresponding standard error, following some previous studies [12,28,29]. The pooled results are calculated using Equation (2). A maximum likelihood test is then run for members and non-members of both groups with the pooled sample, yielding values of 13.2462 and 10.25374 for the non-marketing group, before and after matching, which fails to reject the null hypothesis that the use of technology is the same for the members and non-members of the marketing group. The technology use for members of the non-marketing group and non-members is identical. The maximum likelihood test of the marketing group yields the value of 17.186078 and 18.184902 before and after matching, which could reject the null hypothesis at $10 \%$ and $5 \%$ significance level, respectively, indicating there is a technology disparity between members and non-members; i.e., cooperative members and non-members operate on different production functions, estimated using Equations (6) and (7). The models fit the data well, with most variables being strongly significant.

Table 6. Parameter estimates for SPF models, unmatched.

\begin{tabular}{|c|c|c|c|c|c|c|}
\hline \multirow{2}{*}{ Variables } & \multicolumn{3}{|c|}{ Non-Marketing Cooperatives } & \multicolumn{3}{|c|}{ Marketing Cooperatives } \\
\hline & Pooled & Non-Member & Member & Pooled & Non-Member & Member \\
\hline Fertilizer(ln) & $\begin{array}{c}0.173 * \\
(2.24)\end{array}$ & $\begin{array}{l}0.164 \\
(1.90)\end{array}$ & $\begin{array}{l}0.204 \\
(1.38)\end{array}$ & $\begin{array}{l}0.173 \text { * } \\
(2.07)\end{array}$ & $\begin{array}{l}0.164 \\
(1.90)\end{array}$ & $\begin{array}{l}0.198 \\
(1.16)\end{array}$ \\
\hline Pesticides $(\ln )$ & $\begin{array}{c}0.176^{* * *} \\
(3.38)\end{array}$ & $\begin{array}{c}0.171 * * \\
(2.77)\end{array}$ & $\begin{array}{l}0.161 \\
(1.73)\end{array}$ & $\begin{array}{c}0.129 * \\
(2.31)\end{array}$ & $\begin{array}{c}0.171 \text { ** } \\
(2.77)\end{array}$ & $\begin{array}{c}-.1920^{* *} \\
(-2.88)\end{array}$ \\
\hline $\operatorname{Bags}(\ln )$ & $\begin{array}{c}0.289^{* * * *} \\
(8.29)\end{array}$ & $\begin{array}{c}0.239^{* * *} \\
(6.66)\end{array}$ & $\begin{array}{c}0.610^{* * *} \\
(6.80)\end{array}$ & $\begin{array}{c}0.267^{* * *} \\
(8.38)\end{array}$ & $\begin{array}{c}0.239^{* * *} \\
(6.66)\end{array}$ & $\begin{array}{c}0.362^{* * *} \\
(23.54)\end{array}$ \\
\hline Hired labor & $\begin{array}{c}0.0550 * * \\
(3.12)\end{array}$ & $\begin{array}{c}0.0542^{* *} \\
(2.74)\end{array}$ & $\begin{array}{c}0.0466 \\
(1.34)\end{array}$ & $\begin{array}{c}0.0597^{* *} \\
(3.26)\end{array}$ & $\begin{array}{c}0.0542 * * \\
(2.74)\end{array}$ & $\begin{array}{l}0.0687 \\
(2.63)\end{array}$ \\
\hline Family labor & $\begin{array}{c}0.472 * * * \\
(8.02)\end{array}$ & $\begin{array}{c}0.479 * * * \\
(7.20)\end{array}$ & $\begin{array}{c}0.613^{* * *} \\
(4.77)\end{array}$ & $\begin{array}{c}0.463^{* * *} \\
(8.37)\end{array}$ & $\begin{array}{c}0.479 * * * \\
(7.20)\end{array}$ & $\begin{array}{l}0.348 \\
(2.39)\end{array}$ \\
\hline Membership & $\begin{array}{c}0.809 * * * \\
(4.36)\end{array}$ & $\begin{array}{l}0 \\
(.)\end{array}$ & $\begin{array}{l}0 \\
(.)\end{array}$ & $\begin{array}{c}0.965^{* * *} \\
(4.91)\end{array}$ & $\begin{array}{l}0 \\
(.)\end{array}$ & $\begin{array}{l}0 \\
(.)\end{array}$ \\
\hline Constant & $\begin{array}{l}1.399 \\
(1.72)\end{array}$ & $\begin{array}{l}1.917^{*} \\
(2.21)\end{array}$ & $\begin{array}{l}-1.448 \\
(-0.83)\end{array}$ & $\begin{array}{c}1.950 \text { * } \\
(2.36)\end{array}$ & $\begin{array}{l}1.917 \text { * } \\
(2.21)\end{array}$ & $\begin{array}{c}4.885 \\
(.)\end{array}$ \\
\hline$\lambda(\operatorname{logit})$ & $\begin{array}{l}2.087 \\
(1.36)\end{array}$ & $\begin{array}{l}2.025^{*} \\
(2.20)\end{array}$ & $\begin{array}{l}-7.126 \\
(-0.06)\end{array}$ & $\begin{array}{l}2.196^{*} \\
(2.16)\end{array}$ & $\begin{array}{c}2.025^{*} \\
(2.20)\end{array}$ & $\begin{array}{l}29.367 \\
(0.13)\end{array}$ \\
\hline$\sigma 2(\ln )$ & $\begin{array}{l}1.605 \\
(1.10)\end{array}$ & $\begin{array}{l}1.320 \\
(1.52)\end{array}$ & $\begin{array}{c}-0.0883 \\
(-0.49)\end{array}$ & $\begin{array}{l}1.548 \\
(1.59)\end{array}$ & $\begin{array}{l}1.320 \\
(1.52)\end{array}$ & $\begin{array}{l}1.0110 \\
(2.04)\end{array}$ \\
\hline $\mathrm{N}$ & 364 & 278 & 86 & 343 & 278 & 65 \\
\hline
\end{tabular}

$\mathrm{t}$ statistics in parentheses. $\sigma 2=\sigma(\mathrm{u}) 2+\sigma(\mathrm{v}) 2, \lambda=\sigma(\mathrm{u}) 2 / \sigma 2,{ }^{*} p<0.05,{ }^{* *} p<0.01,{ }^{* * *} p<0.001$. 
Table 7. Parameter estimates for SPF models, matched.

\begin{tabular}{ccccccc}
\hline \multirow{2}{*}{ Variables } & \multicolumn{2}{c}{ Non-Marketing Cooperatives } & \multicolumn{3}{c}{ Marketing Cooperatives } \\
\cline { 2 - 7 } & Pooled & Non-Member & Member & Pooled & Non-Member & Member \\
\hline Fertilizer(ln) & $0.182^{*}$ & 0.188 & 0.148 & 0.1794 & 0.202 & $-0.187^{* * *}$ \\
& $(2.04)$ & $(1.96)$ & $(1.02)$ & $(1.42)$ & $(1.52)$ & $(-4262.52)$ \\
Pesticides(ln) & $0.199^{* * *}$ & $0.233^{* *}$ & 0.156 & 0.108 & $0.192^{*}$ & $-0.129^{* * *}$ \\
& $(3.34)$ & $(3.07)$ & $(1.73)$ & $(1.36)$ & $(2.00)$ & $(-15350.88)$ \\
Bags(ln) & $0.296^{* * *}$ & $0.200^{* * *}$ & $0.568^{* * *}$ & $0.255^{* * *}$ & $0.214^{* * *}$ & $0.381^{* * *}$ \\
& $(5.69)$ & $(5.52)$ & $(6.17)$ & $(7.05)$ & $(5.14)$ & $(160400.86)$ \\
Hired labor & $0.0702^{* * *}$ & 0.0464 & 0.0552 & $0.072^{*}$ & $0.0655^{*}$ & $0.0134^{* * *}$ \\
& $(3.37)$ & $(1.68)$ & $(1.63)$ & $(2.75)$ & $(2.15)$ & $(2769.99)$ \\
Family labor & $0.524^{* * *}$ & $0.418^{* * *}$ & $0.645^{* * *}$ & $0.449^{* * *}$ & $0.535^{* * *}$ & $0.247^{* * *}$ \\
& $(6.62)$ & $(4.65)$ & $(4.99)$ & $(5.59)$ & $(4.47)$ & $(13610.47)$ \\
Membership & $0.969^{* * *}$ & 0 & 0 & $0.906^{* *}$ & 0 & 0 \\
& $(4.31)$ & $()$. & $()$. & $(3.44)$ & $()$. & $()$. \\
Constant & 0.798 & $2.420^{*}$ & -0.878 & 2.373265 & 1.512 & $7.709^{* * *}$ \\
& $(0.74)$ & $(2.27)$ & $(-0.50)$ & $(1.81)$ & $(1.03)$ & $(25265.29)$ \\
$\lambda(\operatorname{logit})$ & 1.957 & $2.796^{* * *}$ & -6.843 & $1.985^{*}$ & $1.895^{*}$ & 34.69 \\
& $(1.67)$ & $(3.65)$ & $(-0.06)$ & $(0.763)$ & $(2.33)$ & $(0.20)$ \\
$\sigma 2(\ln )$ & 1.273 & $0.881^{*}$ & -0.151 & 1.247418 & 1.075 & $1.545^{* * *}$ \\
& $(1.03)$ & $(2.11)$ & $(-0.79)$ & $(0.670)$ & $(1.58)$ & $(48.98)$ \\
$\mathrm{N}$ & 259 & 175 & 84 & 195 & 133 & 62 \\
\hline
\end{tabular}

For both groups, before and after matching, the coefficients are positively and strongly significant, suggesting cooperative membership is associated with higher output, which corresponds to previous studies $[9,12,16,30]$. Before matching, fertilizer use in the pooled samples is positively related to output, but not significantly so when using separate production functions. Pesticides have a stronger influence on output than fertilizers, while the coefficients for the marketing members are negatively related to output before and after matching and positive for all other groups. This indicates that members of the marketing cooperatives did not benefit from using more pesticides on their apples, as the use of pesticides influences output negatively. Bags, amongst all inputs, are the most significant input positively relating to output. For all matched and unmatched groups, bags expense is correlated to higher output. Another strongly positive input is the number of family laborers, which indicates higher output at a higher magnitude than bags. Against this, hired labor is also positively related to output but to a much lower degree. Investment in hired labor does not contribute to profits as much as family laborers. For most smallholders, family labor is considered free but dedicated; for such labor-intensive industry as apple production, having more family labor available and putting more effort into the field may increase productivity.

\subsection{Technical Efficiency Scores (TE)}

The technical efficiency (TE) scores, estimated using Equation (2), are presented in Table 8. The TE obtained using Equations (6) and (7) are presented in Table 9. The maximum likelihood ratio test has proven that separate functions for the non-marketing group are necessary. Using the conventional production function to compare members and non-members would be inaccurate. The acceptance of the null hypothesis for the marketing group proves the conventional function sufficient for both members and non-members; however, separate functions for the marketing group are also calculated for comparison. Using the pooled function, the average TE of non-members is slightly higher than members, although the difference is not significant. 
Table 8. Technical efficiency (TE) scores using conventional functions.

\begin{tabular}{ccccccc}
\hline TE & & N & Non-Member & N & Member & Mean-Diff \\
\hline \multirow{2}{*}{ Marketing } & Unmatched pooled & 278 & 0.525 & 65 & 0.516 & 0.009 \\
\cline { 2 - 7 } & Matched pooled & 133 & 0.451 & 62 & 0.449 & 0.002 \\
\hline \multirow{2}{*}{ Non-marketing } & Unmatched pooled & 278 & 0.560 & 86 & 0.557 & 0.003 \\
\cline { 2 - 7 } & Matched pooled & 175 & 0.532 & 84 & 0.531 & 0.001 \\
\hline
\end{tabular}

Table 9. TE scores using separate functions.

\begin{tabular}{|c|c|c|c|c|c|c|c|c|}
\hline & TE Non-Marketing & Mean & $\mathbf{N}$ & Mean-Diff & TE marketing & Mean & $\mathbf{N}$ & Mean-Diff \\
\hline \multirow{2}{*}{ Unmatched } & Member & 0.990 & 86 & \multirow{2}{*}{$0.476^{* * *}$} & Member & 0.332 & 65 & \multirow{2}{*}{$-0.182^{* * *}$} \\
\hline & Non-member & 0.514 & 278 & & Non-member & 0.514 & 278 & \\
\hline \multirow{2}{*}{ Matched } & Member & 0.988 & 84 & \multirow{2}{*}{$0.589^{* * *}$} & Member & 0.366 & 62 & \multirow{2}{*}{-0.074 * } \\
\hline & Non-member & 0.399 & 175 & & Non-member & 0.440 & 133 & \\
\hline
\end{tabular}

However, when separate frontiers are used, the average TE of non-marketing members is much higher than non-members. Because the TE of members and non-members are calculated using difference functions, this does not mean non-marketing members have access to better technology, but suggests that non-marketing members have little deviation from the best possible frontier. The unmatched non-members for the non-marketing group achieved TE of 0.514, but the score has gone down to 0.399 after matching, while the TE of non-marketing members is both above 0.9 before and after matching. Under different production functions, the TE difference between non-marketing members and non-members with similar characteristics is larger, which means the non-marketing type of cooperatives are highly effective in enhancing smallholder farmers' efficiency.

In contrast to the non-marketing group, the average TE of marketing members is lower than non-members under the conventional function or separate functions. Using separate production functions, the average TE of marketing members is still lower than for non-members. Even though the marketing-cooperative membership is positively related to output, such cooperatives cannot increase efficiency for its members. The distinguishing function of these types of cooperatives is that they negotiate wholesales with dealers on behalf of the farmers to gain a stronger price negotiating power. Farmers do not need to look for marketing channels. The results suggest that marketing cooperatives do not result in greater TE, nor do direct access to marketing channels and price negotiating power.

\section{Discussion}

This paper has used the PSM procedure to examine the factors influencing farmers' decisions on whether to join a cooperative and used the SPF model to examine factors influencing farmers' TE. The homogeneity between the production frontiers of cooperative members and non-members was tested. The hypothesis that there existed the same production frontier for cooperatives that do not provide marketing services and non-cooperatives was rejected. The null hypothesis that the marketing cooperatives and non-cooperatives share the same production frontier was accepted.

Having estimated separate production frontiers, this paper then examined the TE levels attained by different groups. The innovation in this regard is that cooperatives are divided into two types: the non-marketing group comprises the traditional agricultural cooperatives that provide farmers with production management support and farming advice, and marketing cooperatives provide marketing and wholesale services to farmers in addition to other services. The results show that both types of cooperative membership are positively related to higher output. However, while members of non-marketing cooperatives achieve the highest TE, membership of marketing cooperatives makes a limited contribution towards increasing farmers' TE. The data were randomly collected from 432 households in China's main apple-producing provinces in 2019. The numbers given by the farmers reflect their actual output and inputs in 2018, when frost disasters took place in some counties; this led 
to exceptionally low output and production costs for some households, which may have brought down the overall efficiency level of apple farmers in China.

In general, the efficiency level achieved by Chinese apple farmers is rather low (FAOSTAT). As a major apple-producing country, most of China's apple orchards are run by smallholder farmers who cannot reach the requisite scale for efficient production and cannot easily construct infrastructure such as irrigation systems. Small-scale production also makes it more difficult to apply production and food safety standards, which in turn reduces TE and apple quality. In addition, efficiency levels are severely reduced by the failure of some agricultural cooperatives to identify and address smallholder farmers' actual needs; i.e., quality assurance and labor management rather than marketing and price negotiating.

To help apple farmers increase production efficiency, policies should be developed and implemented that facilitate the participation of family laborers in agricultural production. Availability of family labor is the most significant input positively related to output; having more family labor available and paying more time in apple production is key to enhanced efficiency. Bags are also significantly related to higher output, while fertilizer is not significant for most groups, suggesting that it is potentially possible to increase TE by using less fertilizer.

A limitation of the research presented here is that only externally observable characteristics such as age and orchard size were taken into account during the sample selection procedure, whereas unobservable but measurable characteristics like farmer personality characteristics, or factors that motivate farmers, was not considered. This might be usefully considered in future research.

Policies should be implemented that encourage the founding and supervision of effective cooperatives. There is a need for farmers to improve the technical efficiency of apple production. This research suggests that cooperative membership can improve TE, although marketing is not a useful cooperative function in this regard. More research is required to assess whether similar findings apply to other production systems.

Author Contributions: Conceptualization, R.Q. and J.C.; methodology, R.Q.; software, R.Q.; validation, Y.W., J.C.; formal analysis, R.Q. and J.C.; investigation, R.Q., J.C., S.J., W.L., and Q.C.; resources, J.C.; data curation, R.Q. and J.C.; writing—original draft preparation, R.Q.; writing-review and editing, G.D.J., W.L., S.J., Q.C., Y.C., G.Y., Z.L., and L.J.F.; visualization and editing, R.Q.; supervision, J.C. and Y.W.; project administration, J.C.; funding acquisition, J.C. All authors have read and agreed to the published version of the manuscript.

Funding: This study is funded by the National Key Research and Development Program of China (2017YFE0122500).

Conflicts of Interest: The authors declare no conflict of interest.

\section{References}

1. Clark, B.; Jones, G.D.; Kendall, H.; Taylor, J.; Cao, Y.; Li, W.; Zhao, C.; Chen, J.; Yang, G.; Chen, L.; et al. A proposed framework for accelerating technology trajectories in agriculture: A case study in China. Front. Agric. Sci. Eng. 2018, 485-498. [CrossRef]

2. Chaddad, F.R.; Iliopoulos, C. Control Rights, Governance, and the Costs of Ownership in Agricultural Cooperatives. Agribusiness 2012, 29, 3-22. [CrossRef]

3. Liang, Q.; Hendrikse, G. Cooperative CEO Identity and Efficient Governance: Member or Outside CEO? Agribusiness 2013, 29, 23-38. [CrossRef]

4. Valentinov, V.; Iliopoulos, C. Economic theories of nonprofits and agricultural cooperatives compared: New perspectives for nonprofit scholars. Nonprofit Volunt. Sect. Q. 2013, 42, 109-126. [CrossRef]

5. Bijman, J.; Hendrikse, G.W.J.; Van Oijen, A. Accommodating Two Worlds in One Organisation: Changing Board Models in Agricultural Cooperatives. Manag. Decis. Econ. 2012, 34, 204-217. [CrossRef]

6. Liang, Q. Combing and Thinking on domestic and foreign cooperative literature from 2012 to 2014. Agric. Econ. Issues 2015, 36, 97-107. (In Chinese)

7. Fischer, E.; Qaim, M. Linking Smallholders to Markets: Determinants and Impacts of Farmer Collective Action in Kenya. World Dev. 2012, 40, 1255-1268. [CrossRef]

8. Cechin, A.; Bijman, J.; Pascucci, S.; Zylbersztajn, D.; Omta, O. Drivers of pro-active member participation in agricultural cooperatives: Evidence from Brazil. Ann. Public Coop. Econ. 2013, 84, 443-468. [CrossRef] 
9. Ito, J.; Bao, Z.; Su, Q. Distributional effects of agricultural cooperatives in China: Exclusion of smallholders and potential gains on participation. Food Policy 2012, 37, 700-709. [CrossRef]

10. Deng, H.; Xu, Z.; Ying, R.; Liao, X. Why is a real farmer professional cooperative hard to find in China?-A framework explanation and empirical facts. China Rural Obs. 2016, 4, 72-83, 96-97. (In Chinese)

11. Pan, J. China farmers' Professional Cooperatives: Interpretation behind the data. China Rural Obs. 2011, 6, 2-11. (In Chinese)

12. Ma, W.; Renwick, A.; Yuan, P.; Ratna, N. Agricultural cooperative membership and technical efficiency of apple farmers in China: An analysis accounting for selectivity bias. Food Policy 2018, 81, 122-132. [CrossRef]

13. Wu, C. Comparative analysis of the efficiency of different modes of farmer cooperatives based on a survey of 440 sample farmers in Guangdong and Anhui Province in 2012. Agric. Econ. Issues 2013, 34, 79-86. (In Chinese)

14. Liu, S.; Cao, J.; Zhang, Y. The relationship between the organizational model of farmers and its technical efficiency-An analysis considering the heterogeneity of samples. Agric. Technol. Econ. 2019, 12, 68-79. (In Chinese)

15. Huang, Z.; Peng, W. Evaluation and Discussion on production technology efficiency of farmers' Cooperatives-Evidence from 5 towns (townships) of Dangshan County, Anhui Province. Agric. Technol. Econ. 2016, 8, 4-14. (In Chinese)

16. Wanglin, M.; Awudu, A. Does cooperative membership improve household welfare? Evidence from apple farmers in China. Food Policy 2016, 58, 58-67.

17. China Statistics Press. China Rural Statistical Yearbook; China Statistics Press: Beijing, China, 2017.

18. Wang, L.; Huo, X.; Kabir, S. Technical and cost efficiency of rural household apple production. China Agric. Econ. Rev. 2013, 5, 391-411. [CrossRef]

19. Shi, H.; Wang, J.; Wang, Y. An Empirical Study on the production efficiency of apple industry in Hebei Province Based on DEA. Agric. Technol. Econ. 2011, 10, 86-91. (In Chinese)

20. Aigner, D.; Lovell, C.; Schmidt, P. Formulation and estimation of stochastic frontier production function models. J. Econom. 1977, 6, 21-37. [CrossRef]

21. Bravo-Ureta, B.; Greene, W.; Solís, D. Technical efficiency analysis correcting for biases from observed and unobserved variables: An application to a natural resource management project. Empir. Econ. 2011, 43, 55-72. [CrossRef]

22. Abdulai, A.-N.; Abdulai, A. Examining the impact of conservation agriculture on environmental efficiency among maize farmers in Zambia. Environ. Dev. Econ. 2017, 22, 177-201. [CrossRef]

23. Khandker, S.R.; Koolwal, G.B.; Samad, H.A. Handbook on Impact Evaluation: Quantitative Methods and Practices; World Bank: Washington, DC, USA, 2010.

24. Gonzalez-Flores, M.; Bravo-Ureta, B.E.; Solís, D.; Winters, P.C. The impact of high value markets on smallholder productivity in the Ecuadorean Sierra: A Stochastic Production Frontier approach correcting for selectivity bias. Food Policy 2014, 44, 237-247. [CrossRef]

25. Jin, L. Research on Key Points of Improving Quality and Efficiency of Shaanxi Apple. Master's Thesis, Northwest University of Agriculture and Forestry Science and Technology, Yangling, China, 2017. (In Chinese).

26. Qiao, Z.; Huo, X.; Zhang, B. The impact of the aging of agricultural labor force on the production efficiency of labor-intensive agricultural products: An Empirical Study Based on 745 Apple households in Shaanxi and Gansu. Econ. Longit. Latit. 2018, 35, 73-79. (In Chinese)

27. Cai, H.; Huang, L. What is agricultural feminization: Discussion and reflection. J. Agric. For. Econ. Manag. 2017, 16, 652-659. (In Chinese)

28. Abdul-Rahaman, A.; Abdulai, A. Do farmer groups impact on farm yield and efficiency of smallholder farmers? Evidence from rice farmers in northern Ghana. Food Policy 2018, 81, 95-105. [CrossRef]

29. Bravo-Ureta, B.; González-Flores, M.; Greene, W.; Solís, D. Technology and Technical Efficiency Change: Evidence from a Difference in Differences Selectivity Corrected Stochastic Production Frontier Model. Am. J. Agric. Econ. 2020, 1-24. [CrossRef]

30. Mojo, D.; Fischer, C.; Degefa, T. The determinants and economic impacts of membership in coffee farmer cooperatives: Recent evidence from rural Ethiopia. J. Rural Stud. 2017, 50, 84-94. [CrossRef] 